\title{
Critérios de noticiabilidade orientadores do agendamento do conteúdo policial com foto na capa dos jornais paranaenses Diário dos Campos e Jornal da Manhã ${ }^{1}$
}

\author{
Newsworthiness criteria orientend by the scheduling of police content with \\ cover photograph in the paranaenses newspappers Diário dos Campos and \\ Jornal da Manhã
}

\section{Criterios de noticiabilidad direccionadores de los contenidos de el Periodismo Policial con la imagen en la portada de los periódicos paranaenses Diário dos Campos y Jornal da Manhã}

\author{
Andressa Kaliberda ${ }^{2}$ \\ Felipe Simão Pontes ${ }^{3}$ \\ Paula Melani Rocha ${ }^{4}$
}

Resumo

A investigação fundamentou-se nos conceitos de Agendamento Midiático, Jornalismo Policial e Critérios de Noticiabilidade. Analisou-se o agendamento do conteúdo policial com foto nas capas dos impressos Diário dos Campos e Jornal da Manhã, bem como a relação entre o texto e a imagem fotojornalística nesse processo. Como metodologia utilizou-se análise de conteúdo, tendo como recorte a primeira semana de cada mês par do ano de 2014, em ambos os diários. A análise identificou uma tendência pela publicação de temas oriundos de releases oficiais e, no caso do Jornal da Manhã, a utilização de chamadas de capa para conteúdos publicados nas páginas internas com o formato nota. Os valores-notícia mais encontrados foram "proximidade", "impacto", "raridade", "surpresa" e "tragédia/drama".

Palavras-Chave: Critérios de Noticiabilidade; Agendamento Midiático; Jornalismo Policial; Jornalismo Regional.

\begin{abstract}
The present investigation is based in the Media Schedule, Police Journalism and Newsworthiness criteria concepts. It was analyzed the scheduling of the police content with cover photographs printed on the Diário dos Campos and the Jornal da Manhã, as well the relation between the text and the photojournalistic image in this process. As methodology it was used the analysis of content, having as snip the first week of each pair month of 2014, in both newspapers. The analysis identified a tendency
\end{abstract}

\footnotetext{
${ }^{1}$ A reflexão proposta apresenta os resultados da pesquisa de mestrado desenvolvida no Programa de PósGraduação em Jornalismo da Universidade Estadual de Ponta Grossa que teve como objeto de estudo o agendamento midiático da editoria de polícia no jornalismo diário em Ponta Grossa - PR.

${ }^{2}$ Mestre pelo Programa de Pós-Graduação em Jornalismo da Universidade Estadual de Ponta Grossa (UEPG). Graduada em Jornalismo pela UEPG. E-mail: andressa.kaliberda@gmail.com

${ }^{3}$ Professor da Pós-Graduação (Mestrado) e do Departamento de Jornalismo da Universidade Estadual de Ponta Grossa (UEPG). Pós-doutor em Jornalismo pela UEPG. Doutor em Sociologia Política pela Universidade Federal de Santa Catarina (UFSC). Mestre em Jornalismo pela UFSC. Graduado em Jornalismo pela Universidade Estadual de Ponta Grossa (UEPG). E-mail: felipe271184@ yahoo.com.br.

${ }^{4}$ Professora da Pós-Graduação (Mestrado) e do Departamento de Jornalismo da Universidade Estadual de Ponta Grossa (UEPG). Pesquisadora colaboradora do LabJor da UNICAMP. Mestre e doutora em Sociologia pela Universidade Federal de São Carlos (UFSCAR). Pós-doutora em Jornalismo pela Universidade Fernando Pessoa (PT). E-mail: paulamelani@gmail.com.
}

Comun. \& Inf., Goiânia, GO, v. 21, n. 1, p. 2-19, jan./mai. 2018 
for publishing themes derivative of oficial releases and, in the case of the Jornal da Manhã, the utilization of cover calls for content published on the internal pages with note format. The news values more found were "proximity", "impact", "rarity", "surprise" and "tragedy/drama".

Keywords: Newsworthiness criteria. Media Schedule. Police Journalism. Regional Journalism.

\section{Resumen}

Esta investigación se basa en los conceptos de la programación de los medios de comunicación, los criterios de Periodismo Policial y el interés periodístico. Se analizó la programación del contenido de la policía con la foto impresa en la portada del Diario dos Campos y Jornal da Manhã, y la relación entre la imagen y el texto de fotoperiodismo en el proceso. La metodología que utiliza el análisis de contenido, con el corte de la primera semana de cada mes par de 2014, en ambas revistas. El análisis identificó una tendencia a problemas de publicación derivados de las versiones oficiales y en el caso del Jornal da Manhã, el uso de artículos de portada para el contenido publicado en las páginas interiores con el formato de nota. Los valores-noticiasías más encontrados fueron "proximidad", "impacto", "raro", "sorpresa" y "tragedia / drama".

Palabras clave: Criterios de noticiabilidad. Horario de los medios de comunicación. Periodismo policial. El periodismo regional.

\section{INTRODUÇÃO}

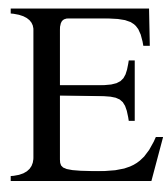

m uma perspectiva macro, o jornalismo regional passa pelas transformações do mundo jornalístico no contexto do século XXI, envolvendo modelo de gestão, cultura profissional, processo de produção impactado pela tecnologia e pela internet, alternância na morfologia das redações e emergência de novas funções e cargos. Contudo, em uma perspectiva micro, o jornalismo apresenta peculiaridades, sobretudo os jornais com foco na cobertura local. A gênese do jornalismo brasileiro é o jornalismo regional e ainda hoje no país, ao considerar os impressos, não há efetivamente um jornal com cobertura nacional. Semelhante aos impressos classificados como "grande mídia" ou mídia tradicional, os impressos regionais "tradicionais" replicam a mesma lógica das relações econômicas e políticas da grande imprensa, só que nas esferas locais e regionais. Essa transposição repercute ainda em uma queda crescente do profissionalismo, com enxugamento do quadro de jornalistas das redações, acúmulo de funções/cargos e, consequentemente, com mudanças no processo de produção do conteúdo noticioso.

O jornalismo regional é um dos objetos de estudo do campo do Jornalismo, na medida em que analisa o processo de produção de conteúdo, as relações com as fontes e os atores sociais, a rotina produtiva e o perfil do profissional, entre outras questões que norteiam o mundo do imprensa.

Nesse sentido, esta reflexão buscou entender as especificidades da cobertura policial realizada por dois impressos regionais, sediados em Ponta Grossa, interior do Paraná, em

Comun. \& Inf., Goiânia, GO, v. 21, n. 1, p. 2-19, jan./mai. 2018 
especial, a análise do agendamento das notícias de violência/segurança nas capas dos diários ponta-grossenses em 2014; e de modo geral, procurou levar à reflexão sobre o tratamento da editoria de polícia no jornalismo regional do interior.

$\mathrm{O}$ artigo traz os resultados da dissertação desenvolvida junto ao Programa de Pósgraduação em Jornalismo da Universidade Estadual de Ponta Grossa, que teve como escopo instigar pesquisas com objeto em jornalismo.

O jornalismo é construído a partir de critérios que orientam a escolha de determinados assuntos na agenda midiática diariamente. Os temas pautados têm relação direta com aquilo que os profissionais da imprensa consideram como sendo de interesse público de acordo com uma cultura pré-estabelecida. As notícias sobre criminalidade, acidentes, tragédias, catástrofes naturais e insólito permeiam a atividade jornalística desde seu princípio, como relata a tese de Peucer $(2004)^{5}$. Ademais, hipoteticamente, a cobertura policial é um dos assuntos diariamente mais pautados nos noticiários regionais, principalmente naqueles sediados nas cidades do interior, com grande visibilidade nas primeiras páginas.

A pesquisa analisou os elementos das chamadas de capa com foto que remeteram à página de polícia dos diários Jornal da Manhã (JM) e do Diário dos Campos (DC). Entre os elementos estudados, considerou-se título, texto e imagem. Também foi verificado se as imagens contribuíram para que as notícias policiais fossem agendadas nas primeiras páginas e se os critérios de noticiabilidade das chamadas dialogavam com os critérios de noticiabilidade presentes nas imagens de capa.

A escolha dos dois jornais se deu por serem os principais veículos impressos da região dos Campos Gerais e por serem os dois únicos impressos em circulação, em Ponta Grossa. Ambos são diários, com edições de terça-feira a domingo e circulam nos municípios de abrangência da cidade-sede Ponta Grossa (PR). O Diário dos Campos é considerado um dos jornais mais antigos do Paraná. Foi fundado em 27 de abril de 1907 sob o título de $O$ Progresso. Somente em 1913 recebeu o nome de Diário dos Campos. O jornal parou de circular por nove anos entre 1990 e 1999. Atualmente, a publicação tem uma tiragem média de 11,5 mil exemplares/dia.

\footnotetext{
${ }^{5}$ Tobias Peucer apresentou, em 1690, a primeira tese sobre jornalismo do mundo, na Universidade de Leipzig, na Alemanha. De Relationibus Novellis, ou traduzido para o português, Os Relatos Jornalísticos, traz uma sistematização dos principais conceitos relativos à imprensa periódica da época. Em 29 parágrafos, o autor traça uma comparação entre jornalismo e história, discutindo assuntos como autoria, noticiabilidade, credibilidade e critérios de seleção das notícias.
}

Comun. \& Inf., Goiânia, GO, v. 21, n. 1, p. 2-19, jan./mai. 2018 
Por sua vez, auto declarado o jornal mais antigo de circulação ininterrupta da região Centro-sul do Paraná, o Jornal da Manhã circula desde 4 de julho de 1954 em Ponta Grossa e na região dos Campos Gerais. Tem cerca de 12 mil exemplares/dia e afirma ter como princípio o jornalismo público. ${ }^{6}$ Ambos são tradicionais na cidade.

A fim de estudar quais elementos contribuem para o agendamento das chamadas policiais com foto na capa dos diários, optou-se pela metodologia análise do conteúdo e partiu das seguintes variáveis: tema das ocorrências pautadas pelos jornais; crédito do texto ${ }^{7}$ e da fotografia; formato do texto e das chamadas de capa; hierarquia dos conteúdos jornalísticos publicados; e os principais elementos que compõem as imagens. A discussão teórica fundamentou-se nos conceitos de Agendamento Temáticos, Critérios de Noticiabilidade e Jornalismo Policial.

Para McCombs (2009, p.154), a teoria do Agendamento perpassa por três instâncias: agenda da mídia, agenda pública e outras agendas. $\mathrm{O}$ autor explica que essas agendas interferem-se mutuamente e pautam os temas debatidos na agenda pública. Os estudos que se desenvolvem na aplicação dessa teoria precisam utilizar instrumentos metodológicos que expliquem o modo como se relacionam essas três instâncias de agendamento. A pesquisa apresentada não teve por objetivo explicar como a agenda pública manifesta os temas ligados à polícia, nem o processo de produção da agenda governamental/policial. O interesse centrouse no agendamento midiático, no modo como os jornalistas apropriaram-se e apresentaram o tema policial.

$\mathrm{O}$ agendamento considera o jornalismo como uma seleção de fatos que tenta dar dicas ao público sobre quais temas têm importância no debate social. Isso acontece à medida que os fatos sociais são dispostos na agenda de acordo com graus de importância aferidos pelos jornalistas. Eles fazem isso a partir do que pressupõem ser de interesse público, baseado em seus conhecimentos teóricos, vivência prática, rotinas de produção, linha editorial, escolha das fontes e na representação do público-alvo. Os meios também aferem graus de importância aos fatos sociais. Isso se dá por fatores diversos no processo de agendamento, em especial o modo como se organiza a produção da notícia. Esse processo de produção, segundo Pontes e Silva (2012), é constatado no produto, na forma de apresentação dos conteúdos jornalísticos, tais como o espaço que determinado acontecimento tem em detrimento de outro, o lugar que

\footnotetext{
${ }^{6} \mathrm{O}$ dado sobre a tiragem média de cada jornal resulta dos números divulgados pelos próprios diários, citando o Instituto Verificador de Circulação (IVC). Esses números podem estar inflacionados devido a questões mercadológicas.

${ }^{7}$ Quanto à autoria do texto, constatou-se que todas as entradas foram atribuídas aos jornais estudados.
}

Comun. \& Inf., Goiânia, GO, v. 21, n. 1, p. 2-19, jan./mai. 2018 
ocupa nas páginas, no caso de um jornal impresso, além do fato de o referido acontecimento ser ou não chamada de capa. Esses elementos conferem graus de importância aos temas abordados midiaticamente e acabam indicando as direções do processo de debate e formação da opinião pública. O que, por conseguinte, motiva a investigação desse processo de agendamento midiático por meio da análise do produto. Nesse sentido, a pesquisa abordou o tema da agenda como a hierarquização temática das capas dos diários ponta-grossenses, a partir do estudo das notícias da editoria de polícia pautadas nas chamadas com foto presentes nas capas do Diário dos Campos e do Jornal da Manhã.

A discussão dos critérios de noticiabilidade partiu da elaboração de Silva (2005; 2014) que sistematizou diferentes contribuições teóricas das últimas quatro décadas para oferecer concepções sobre noticiabilidade, critérios de noticiabilidade e valores-notícia. Para a autora (2014), os critérios de noticiabilidade transformam o potencial de noticiabilidade em critérios regulares que permitem ao jornalista identificar, selecionar, hierarquizar e apresentar as notícias. Ela discrimina os critérios de noticiabilidade em três instâncias:

(1) critérios na origem do fato (seleção primária dos fatos / valores-notícia), com abordagem sobre atributos como conflito, tragédia, proximidade etc; (2) critérios de noticiabilidade no tratamento dos fatos, centrados na seleção hierárquica dos fatos e na produção da notícia, desde condições organizacionais e materiais até cultura profissional; (3) critérios de noticiabilidade na visão dos fatos, sobre fundamentos ético-epistemológicos. (SILVA, 2014, p. 51)

A explicação dos critérios de noticiabilidade ofereceu o recorte para o entendimento de como a autora define valores-notícia, ou os critérios de noticiabilidade na origem do fato. Os valores-notícia estão fundamentados em características dos acontecimentos que são merecedores do conhecimento do público (SILVA, 2014). Essas características estão na relação de valores advindos das rotinas, valores e processos jornalísticos, e a dinâmica de produção dos fatos sociais por diferentes instituições.

No caso específico das imagens e seus valores-notícia, Sousa (2004b) transporta parte dos estudos em jornalismo para a fotografia e o fotojornalismo. Assim, ele emprestou valores como intensidade ou magnitude, surpresa, proximidade, continuidade, previsibilidade, redundância, curiosidade, proeminência social, interesse humano, institucionalidade, conflito, oportunidade, exclusividade para os estudos do fotojornalismo brasileiro. $\mathrm{O}$ uso de imagens pode também conferir maior peso na agenda dos temas. Entretanto, a fotografia tende a modificar os critérios de seleção das notícias principais dos jornais, uma vez que, mesmo 
notícias que contenham os critérios descritos por Galtung e Ruge (1994) como fundamentais no processo de hierarquização dos fatos, podem, muitas vezes, não receber lugar de destaque na primeira página por não possuir uma imagem que chame atenção do leitor. Além das imagens como definidor de valor-notícia, ela também determina critérios de hierarquia, o que, por conseguinte, influencia na definição dos assuntos que estarão na capa (em maior evidência) nos periódicos.

Correia (2010) faz um estudo da aplicação dos principais valores-notícia presentes no jornalismo policial. Ele aponta que o jornalismo policial tem características próprias que agrupam critérios do jornalismo e da literatura, visto a personificação utilizada quando esses acontecimentos são pautados. Correia (2010, p. 65) aponta como principais critérios no jornalismo policial:

- Insólito: é o fato incomum, o conceito é semelhante ao apontado por Galtung e Ruge (1994) como o inesperado;

- Personalização: identificação do leitor com a personagem;

- Dramatização: a forma como a mídia contou o fato, relatando o drama;

- Disponibilidade: a facilidade em obter informações sobre o fato da notícia policial;

- Violência: $o$ ato criminoso em si;

- Consonância: remete a outros acontecimentos semelhantes.

O presente estudo concentrou-se nas duas primeiras instâncias abordadas por Silva (2014) (critérios de noticiabilidade na origem do fato e critérios de noticiabilidade no tratamento dos fatos) para analisar o conteúdo de polícia agendado com foto nas capas do Diário dos Campos e do Jornal da Manhã. Os valores-notícia sistematizados por Silva (2014, p. 65-66) são conceitos e unidades de análise desta pesquisa. Por sua vez, "os critérios de noticiabilidade no tratamento dos fatos" não foram completamente referendados, mas utilizados para estudar o processo de hierarquia dos fatos na apresentação dos conteúdos pelos dois jornais. Assim, o estudo da hierarquia dialogou com a teoria do Agendamento, pois esta indica que quanto maior o destaque na agenda midiática, mais importante dentre as preocupações do público (MCCOMBS, 2009). Corrobora com estas considerações a afirmação de Marcos Paulo Silva (2013, p.214) de que "todo evento dotado de certo grau de noticiabilidade recebe, em geral, um valor noticioso que determina seu posicionamento nas páginas da mídia". Dentre as marcas dessa valorização, explora-se "[...] a proeminência 
jornalística do acontecimento (o volume de itens noticiosos, o espaço físico que eles ocupam e suas posições hierárquicas nos veículos de comunicação) [...]"8.

\section{PROCEDIMENTOS DA PESQUISA}

Definiu-se a coleta dos dados às primeiras semanas dos meses pares de 2014: fevereiro, abril, junho, agosto, outubro e dezembro. Deste modo, 36 edições do Diário dos Campos e 36 edições do Jornal da Manhã constituíram o corpus de análise, uma vez que os dois periódicos não circulam na segunda-feira. Somou-se assim, o equivalente a seis semanas de cada jornal. Dentre todas as chamadas de capa que tematizaram a editoria de polícia destas 72 edições, foram selecionadas como unidades de análise as chamadas que apresentavam fotos na capa.

Durante o período escolhido como recorte há dois meses de sazonalidade. $\mathrm{Na}$ primeira semana de outubro de 2004, aconteceram as eleições para cargos majoritários e proporcionais, em níveis estadual e federal. Na primeira semana de dezembro ocorreu a festa mais tradicional de Ponta Grossa, que atrai visitantes de toda a região. A München Fest recebeu apoio dos dois periódicos.

Os dois jornais apresentam em seu projeto editorial que a área de cobertura abrange 22 municípios da região dos Campos Gerais: Arapoti, Carambeí, Castro, Guamiranga, Imbaú, Ipiranga, Irati, Ivaí, Jaguariaíva, Ortigueira, Palmeira, Piraí do Sul, Porto Amazonas, Ponta Grossa, Prudentópolis, Reserva, São João do Triunfo, Sengés, Teixeira Soares, Telêmaco Borba, Tibagi e Ventania.

Durante o período analisado por esta pesquisa, o Jornal da Manhã (JM) contava com dois fotojornalistas, seis repórteres, um editor chefe e o diretor executivo ${ }^{9}$. Já o Diário dos Campos (DC) dispunha de nove repórteres, dois fotojornalistas, a chefe de redação e a diretora geral, além do presidente da empresa ${ }^{10}$.

A pesquisa utilizou o termo jornalismo policial ou conteúdo de polícia por esse ser o título dado à editoria dedicada ao assunto no Diário dos Campos. No Jornal da Manhã, ainda que a editoria chame-se "Cotidiano", o box que caracteriza a página na qual são publicados acontecimentos relativos ao tema chama-se Giro Policial, reforçando o uso do termo. Assim,

\footnotetext{
8 Além deste item de verificação, Silva (2013, p. 214) indica a análise das fontes utilizadas e os eventos atributivos relacionados ao acontecimento em pauta, itens não explorados nesta pesquisa.

${ }^{9}$ Esses dados são de 2014, ano de referência da análise.

${ }^{10}$ Esses dados são de 2014, ano de referência da análise.
}

Comun. \& Inf., Goiânia, GO, v. 21, n. 1, p. 2-19, jan./mai. 2018 
tendo em vista as diferenças conceituais sobre jornalismo policial (ANGRIMANI, 1995; FUCCIA, 2008; WAINBERG, 2005) e jornalismo de segurança (ALVIM, 2014; ROLIM, 2006) e as características de cobertura jornalística local, optou-se por utilizar o termo adotado pelos diários ponta-grossenses.

O JM tem, em sua página policial, uma secção que ocupa a lateral de cima a baixo. Esse espaço, que toma duas colunas dos quadrantes 1 e 3 da página tem informações como: "Santo do dia", "Previsão do tempo" e "Obituário". A notícia principal da página acaba sempre ocupando a metade superior da página, devido à secção, mas deslocada para o segundo quadrante. O que caracteriza o espaço, na página $\mathrm{A} 6$, em que essas notícias são publicadas, é a coluna chamada "Giro Policial”, a qual traz sempre um conjunto de três notas rápidas sobre o tema. Além delas, o JM publica 2 a 3 notícias, em média.

Figura 1 - Conteúdo publicado na página policial e agendado na capa Jornal da Manhã do dia 04 de junho de 2014

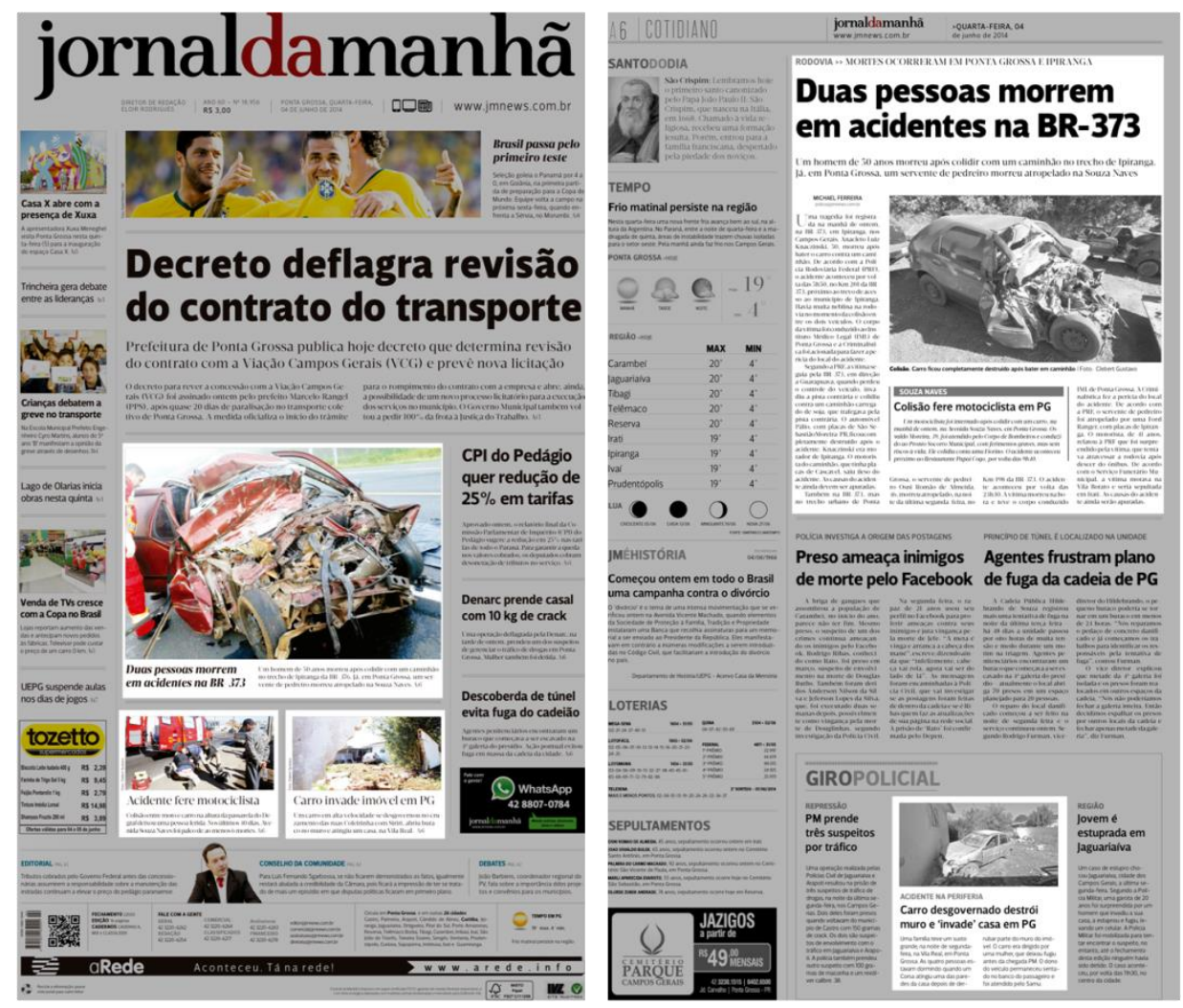

Fonte: Site oficial do Jornal da Manhã

O DC, por sua vez, dedica toda a página à editoria de Polícia. A página 6A quase não possui publicidade e é composta de um conjunto de, em média, 7 a 8 conteúdos jornalísticos 
por edição. Não há colunas nessa página, mas esporadicamente pode ser publicado um espaço dedicado às notas curtas. Esse espaço é denominado "Breves".

Figura 2 - Conteúdo publicado na página policial e agendado na capa do Diário dos Campos do dia 03 de junho de 2014

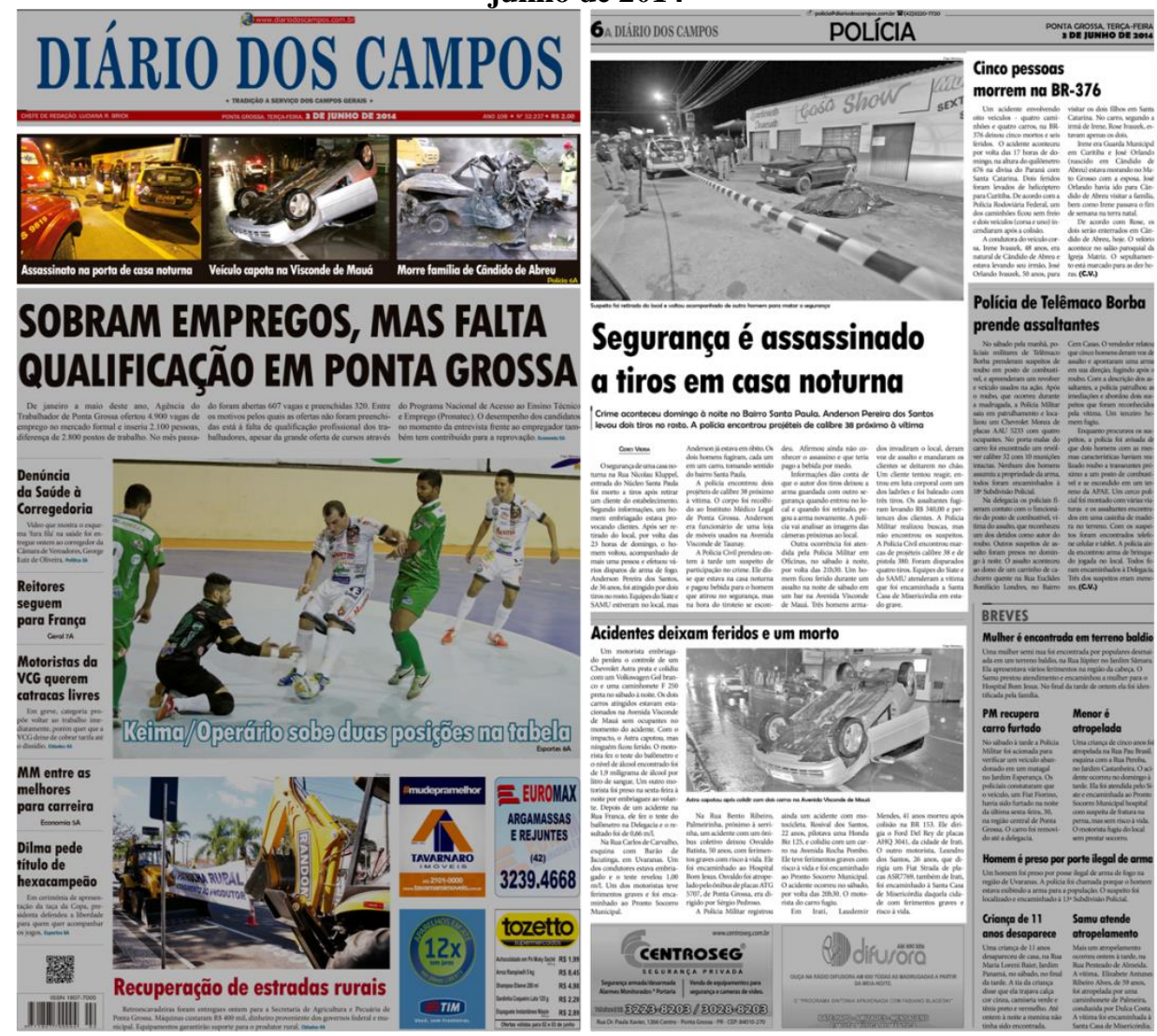

Fonte: Site oficial do Diário dos Campos

Além da posição de quadrantes tradicional (a página dividida em quatro partes e numeradas da esquerda para a direita e de cima para baixo), verificou-se a necessidade incorporar outra classificação para contemplar a análise dos dados. As posições de visualização são categorizadas numericamente conforme explicitado na Figura 3:

Figura 3 - Posição dos textos e chamadas de capa nas páginas dos jornais 

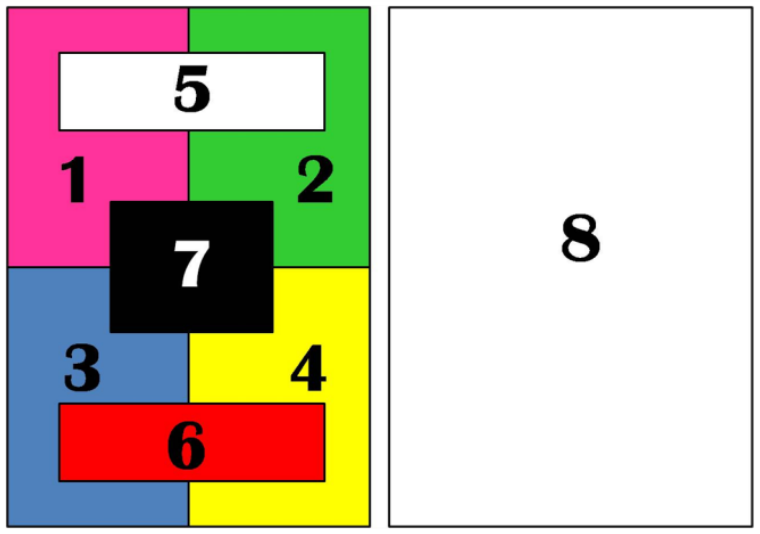

\begin{tabular}{|l|}
\hline Onde: \\
\hline $\mathbf{1}$ = Quadrante 1 \\
\hline $\mathbf{2}$ = Quadrante 2 \\
\hline $\mathbf{3}$ = Quadrante 3 \\
\hline $\mathbf{4}$ = Quadrante 4 \\
\hline $\mathbf{5}$ = Mesma proporção dos quadrantes 1 e 2 \\
\hline 6 = Mesma proporção dos quadrantes 3 e 4 \\
\hline $\begin{array}{l}\text { 7 = Mesma proporção dos quadrantes 1, 2, } 3 \\
\text { e } 4 \text { (centro da página) }\end{array}$ \\
\hline $\mathbf{8}$ = Página inteira \\
\hline
\end{tabular}

Org.: A autora

As posições 5, 6, 7 e 8 foram criadas neste estudo frente à necessidade encontrada durante a observação, já que os jornais, divididos em seis colunas, colocam, muitas vezes, chamadas na região central da página. Assim, essas categorias permitem uma visão mais detalhada de como esses conteúdos são valorizados em relação ao espaço das páginas. Além da posição das chamadas na capa, percebe-se outros elementos que indicam a valorização da chamada, como a porcentagem da mesma em relação ao espaço total da capa e o tipo de chamada. A porcentagem foi dividida em pequena (entre $1 \%$ e $15 \%$ ), média (entre $16 \%$ e $30 \%$ ) e grande (acima de 30\%). Outra categoria considerada diz respeito à autoria do texto e das imagens, identificadas em conteúdo externo e produção própria do jornal analisado.

O tipo de chamada é categorizado com base nos formatos identificados por Cervi (2009, p. 4). O autor aponta, em ordem decrescente, a manchete com foto e sem foto, chamada com e sem foto, foto-legenda e chamada título. Como a pesquisa trabalhou apenas com chamadas que utilizaram fotografia nas capas, essas categorias foram adaptadas para: manchete (somente manchete com foto), foto-legenda (ou foto-chamada) e chamada com foto. A manchete foi considerada a principal chamada da edição, posicionada em um lugar de destaque e construída visualmente para facilitar sua identificação. A diferença entre fotolegenda e chamada com foto foi que nesta existe um pequeno texto explicativo além da imagem e do título da chamada que a acompanha. Esse texto, que publica na capa as principais informações do acontecimento noticiado na página interna, também foi analisado segundo o conceito de critérios de noticiabilidade e de valores-notícia.

O cruzamento desses resultados com os dados do conteúdo publicado nas páginas internas permitiu uma visualização dos formatos jornalísticos pautados como capa nos diários ponta-grossenses. Para tanto, utilizou-se a categorização de gêneros informativos proposta por Lage (2006), que subdivide o jornalismo informativo em nota, notícia, reportagem e 
entrevista. Ao quadro de análise foi acrescentada a categoria "outros" a fim de abranger possíveis formatos que não se enquadravam nos propostos pelo autor.

O tipo de ocorrência que pauta os jornais foi uma das categorias de análise. Para definir as variáveis, utilizou-se o Relatório Estatístico Criminal da Secretaria de Segurança Pública do Paraná (2014), por entender que se trata de um órgão oficial que abrange as principais entidades que pautam o DC e o JM. A partir das categorias utilizadas pelo Relatório, foram feitas adequações à realidade do objeto empírico. Algumas categorias foram agrupadas e criou-se "outros", para classificar ocorrências de menor frequência. A partir desse movimento de adequação das variáveis, obteve-se 10 categorias finais: "acidentes de trânsito com vítimas fatais", "acidentes de trânsito sem vítimas fatais", "homicídios", "lesão corporal/brigas", "roubo/furto", "danos ao patrimônio", "catástrofes naturais", "prisão ou apreensão", "ação governamental" e "outros".

Optou-se por distinguir acidentes de trânsito entre os com vítimas fatais e sem, pois se entende que é uma prática comum no jornalismo policial a valorização da tragédia. Desde o século XVII, Peucer já definia a morte como um acontecimento que merecia ser conhecido pelo público: “[...] as desgraças, as mortes e centenas de coisas mais que façam referência à história natural, à história da sociedade, da Igreja, da literatura: tudo isto costuma ser narrado de forma embaralhada nos periódicos.” (PEUCER, 2004, p. 21). Isso reforça que a morte deve ser considerada na elaboração das categorias, já que o Paraná é o $5^{\circ}$ estado com maior número de mortes no trânsito do país, de acordo com o Anuário Brasileiro de Segurança Pública (2014). Roubos e furtos foram unidos em uma única categoria. No caso dos dados levantados, entendeu-se que não há prejuízo para a pesquisa agregar esses dois tipos de ocorrência. Esse foi o mesmo caso de brigas e lesão corporal.

\section{A HIERARQUIA DO ACONTECIMENTO DE POLÍCIA NA CAPA DOS JORNAIS}

A pesquisa explorou qualitativamente algumas capas consideradas representativas da amostragem e suas respectivas páginas internas, com o propósito de aprofundar aspectos relevantes do processo de agendamento e produção das notícias identificáveis nesses casos. Essa análise qualitativa dialogou com resultados da aferição do levantamento de dados, entendendo que as capas selecionadas trouxeram com mais evidências as estratégias da redação para transformar fatos sociais em acontecimentos jornalísticos, articulando este estudo às teorias do agendamento midiático e de critérios de noticiabilidade. 


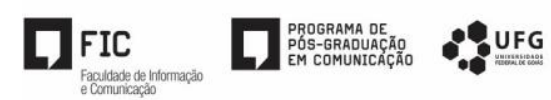

A análise preocupou-se em demarcar o que os dois diários de Ponta Grossa definiram (de acordo com as peculiaridades de seus processos produtivos) como mais importante quando o assunto é segurança pública e todos temas dele decorrentes. Além disso, as similaridades e diferenças oferecem elementos para reflexão sobre o modo como o jornalismo regional exercido no interior trabalha as questões relativas à polícia.

O estudo constatou que o jornalismo policial em Ponta Grossa estrutura-se com base nas informações repassadas por releases oficiais das entidades de segurança pública (Polícias Militar, Civil, Rodoviárias, Corpo de Bombeiros, Instituto Médico Legal, Guarda Municipal, etc). O uso de informações oficiais predominou na escolha dos fatos que compõem o cardápio noticioso do dia. Poucos foram os casos em que os diários utilizaram-se de outras fontes como os envolvidos nos fatos ou testemunhas dos acontecimentos.

A questão da segurança pública praticamente não entrou nos debates dos jornais, fosse através de dados, fosse por proposituras de medidas que pudessem resolver situações que acabaram se tornando rotineiras nas páginas de polícia. No geral, a cobertura focou na particularidade do acontecimento, sem receber desdobramentos como, por exemplo, os motivos que levaram uma região a ter um índice de acidentes de trânsito considerado alto.

Essa falta de desdobramento do fato pode ter diversos motivos, como por exemplo, a dependência das informações fornecidas pelos boletins de ocorrência, o caráter factual do evento policial e a própria cultura jornalística de recorrer a fontes oficiais. Essas informações, provenientes dos órgãos oficiais, foram as mesmas publicadas na chamada de capa. Os jornalistas tinham a foto, as informações principais e o fato era noticiado como uma espécie de fast news. A notícia rápida, fácil de compreender, mas superficial, sem uma sustentação profunda e pluralidade de fontes.

A factualidade foi comprovada pela priorização das ocorrências como acidentes de trânsito na pauta geral dos periódicos. Tanto o Jornal da Manhã quanto o Diário dos Campos se utilizaram dessa estratégia de cobertura temática. Essa consideração ficou evidente na estrutura da editoria, no modo como os jornais selecionaram o que foi para a capa e no uso de imagens que costumaram dialogar com os textos promovendo maior apelação ao conteúdo reportado. Isso demonstra que o Jornalismo Policial local ainda prima pelos fatos do cotidiano policial sem a contextualização aprofundada da informação, tratando o acontecimento em sua singularidade, conforme apontou Rolim (2006), sem a necessária discussão e inclusão de tais factualidades nas mediações que as engendram. Os eventos foram tratados como se recortados da realidade e noticiados de forma independente pelos diários. 
Essa regra pode ser motivada pelas circunstâncias que envolvem a produção jornalística policial local. A abrangência de diversos municípios, o uso de boletins oficiais, o fato de se tratar de jornalismo diário em que os mesmos profissionais alimentam as plataformas online e impressa são fatores que contribuem para que a apuração dos fatos seja mais rasa e a contextualização das ocorrências fique em segundo plano. Demonstra também pouco investimento dos periódicos em profissionais e em processos de apuração de maior fôlego, que demandam mais recursos humano e financeiro. Os jornalistas, fadados a fechar uma página toda em cinco horas, acabam subsumidos por essa rotina.

O fato de Ponta Grossa possuir o maior entroncamento rodoferroviário do Sul do país também contribui para que os acidentes de trânsito sejam constantemente noticiados, sobretudo aqueles que ocorrem nas rodovias. O município possui saída para rodovias federais e estaduais que se convergem e fazem ligação com várias regiões do país. Além disso, as ocorrências de trânsito são fatos que rendem imagens de certa forma impactantes, o que é esperado do jornalismo policial. Isso se confirma ao observar que o impacto esteve presente em praticamente $50 \%$ das imagens que fazem referência à editoria policial publicadas nas capas dos periódicos.

As imagens de acidentes de trânsito contam com uma característica comum: elas têm um enquadramento aberto, que permite visualizar os danos causados pelo acidente e, em muitos dos casos, o local em que o acidente aconteceu. Dessa forma, além do critério de "impacto", essas imagens agregam o valor-notícia "proximidade" à medida em que o fotógrafo escolhe o ângulo que melhor permite a identificação da via, utilizando da linguagem fotojornalística para compor o quadro visual e transmitir a mensagem ao leitor com o maior número de detalhes. A imagem, nesses casos, acaba por criar uma narrativa complementar ao texto, levando para o leitor uma visão do fato que não foi filtrada pelas entidades oficiais de segurança, mas que parte do olhar do jornalista que presenciou o momento imediatamente posterior ao acontecimento.

Paradoxalmente, o agendamento midiático de conteúdos policiais é frequente nos diários locais. A proximidade dos acontecimentos certamente é um valor-notícia que contribuiu para essa tendência em agendar em média um conteúdo policial por dia nas capas dos periódicos. Esse valor-notícia esteve em todos os conteúdos textuais publicados na capa dos impressos. Nos discursos fotográficos, a proximidade foi representada pela rápida identificação do local em que o fato aconteceu, bem como pela identificação sociocultural com os elementos apresentados pelo fotojornalista ou pelo repórter fotográfico no quadro

Comun. \& Inf., Goiânia, GO, v. 21, n. 1, p. 2-19, jan./mai. 2018 
visual. Esse foi um valor-notícia apresentado em mais de $80 \%$ das imagens do Diário dos Campos e em mais de $70 \%$ das fotografias do Jornal da Manhã.

Outros valores-notícia que caracterizaram o conteúdo dos dois jornais foram "raridade", "surpresa", "impacto" e "tragédia/drama". "Ações governamentais" e "justiça" apareceram esporadicamente. $\mathrm{O}$ interessante é que todas as chamadas dos critérios "polêmica" e "justiça" conotaram o trabalho da instituição policial, seja como mérito ou justificando as condições de trabalho, ou ainda, como um serviço da própria instituição.

Essa característica é descrita por Danton (1990) como uma simbiose criada entre o repórter e a fonte, no sentido de pertencimento a um grupo interno entre eles. $\mathrm{O}$ sentimento de pertencimento cria uma simpatia que reflete no teor dos fatos noticiados, como ocorre comumente nas páginas policiais dos diários ponta-grossenses. "O noticiário corre em circuitos fechados: é escrito sobre e para as mesmas pessoas, e às vezes em código privado" (DANTON, 1990, p. 83). Esse fato é presente tanto do DC quanto no JM. No jornalismo policial, para além da repetição de fontes e de fatores que agendam essas notícias nas capas dos jornais, os termos utilizados são bastante recorrentes e peculiares do universo policial, reforçando o quadro de simbiose existente entre o jornalista e a fonte. Termos como 'meliante', 'elemento', entre outros, são frequentemente encontrados nos textos e até nos títulos dos conteúdos informativos. O autor propõe um estudo sociológico que analise essa relação que, segundo ele, é crescente, já que as fontes constituem um elemento importante junto ao seu público.

Quanto ao espaço ocupado pelas imagens, pode-se dizer que, embora a fotografia por si carregue um fator atrativo ao leitor, conforme já foi apontado pelas teorias do fotojornalismo por autores como Lima (1989) e Sousa (2004), os jornais não exploraram em espaço físico as chamadas agendadas com imagem nas capas quando o assunto era policial. Isso foi provado na análise do tamanho das chamadas. O Diário dos Campos teve 71,9\% das chamadas com tamanho pequeno e o Jornal da Manhã teve 89,2\% nesse tamanho. Vale lembrar que essa estatística considerou o conjunto da chamada, ou seja, foto e texto, somados, não chegaram a ocupar, na maioria dos casos, mais de $15 \%$ do espaço total da capa dos periódicos.

Isso demonstra que os jornais, embora utilizassem bastante a imagem como atrativo para as páginas policiais, não o fizeram com grandes destaques. Apenas em um caso isso ocorreu nos dois jornais. Foi no caso de um acidente em que morreram cinco pessoas de uma mesma família. No entanto, mesmo nesse caso o tamanho da chamada, que ultrapassou os 
$30 \%$ da capa de ambos os jornais, não trouxe uma imagem expandida. Foram pequenas imagens compondo o discurso visual da capa. É possível que o cuidado em não ultrapassar a linha tênue que separa o impacto da notícia e a sensacionalização do acontecimento levou ao cuidado em manter as fotografias com um espaço contido, sem muitos alardes para o fato noticiado. Nesse caso, embora o discurso fotográfico aponte para conteúdos que trazem realmente uma narrativa visual, com informações jornalisticamente relevantes para o conjunto da notícia, o destaque que a fotografia recebe acaba por conter o acesso que o leitor poderia ter às informações sobre o fato que não são provenientes das instituições policiais.

Em relação à hierarquia do conteúdo veiculado pelos jornais, percebeu-se uma disparidade no processo seletivo e nas decisões sobre o que deve receber destaque com foto na capa. O Diário dos Campos manteve um padrão, quase natural na observação da hierarquização das informações, visto que o conteúdo destacado na página interna (maior tamanho, presença na primeira dobra e uso de imagens) costumava estar na capa com imagens. Por sua vez, o Jornal da Manhã colocou na capa um número significativo de conteúdos que não receberam destaque na página interna. Houve chamadas com foto para notas, texto sem foto e/ou presentes na segunda dobra da editoria (inclusive no rodapé).

Essa aparente falta de critério revela dinâmicas diferenciadas desse periódico. Primeiro porque é possível indicar que a existência de outro veículo noticioso (on-line) do grupo faz com que parte significativa da produção policial alimente duas mídias, sem necessariamente uma quantidade satisfatória de profissionais para ambas as coberturas. É importante ressaltar que o JM contava com seis repórteres e dois fotógrafos, no momento da pesquisa, já o DC estava com nove repórteres e dois fotógrafos. Além disso, o conteúdo produzido para essa plataforma on-line tem por característica textos curtos e imagens. Segundo, é uma pista de que os fotojornalistas realizam a cobertura in loco sem a presença do repórter, o que leva a suspeitar que o conteúdo de algumas coberturas é redigido por esses profissionais ou pelo editor. Caberia, a partir das informações extraídas dessa pesquisa de conteúdo, novas investigações que estudassem a dinâmica de produção da editoria e das duas redações como um todo.

A partir da abordagem do conjunto dos dados, conclui-se que a imagem é um fator de agendamento importante e muitas vezes decisivo na composição das capas dos dois jornais. Para além de pautar os acontecimentos policiais no Diário dos Campos e no Jornal da Manhã, ela contribui também no processo de hierarquização, valorizando os fatos noticiosos que, sem a presença do conteúdo visual, poderiam não ser agendados nas primeiras páginas.

Comun. \& Inf., Goiânia, GO, v. 21, n. 1, p. 2-19, jan./mai. 2018 
Embora a editoria de Polícia tenha destaque na construção das capas de ambos diários, o conteúdo interno não recebe tanta atenção quanto seria esperado na produção jornalística. As versões oficiais predominaram nos textos e o uso de fontes dificilmente saiu do lugar-comum, valorizando sempre os órgãos de segurança pública que também agendam os periódicos. Assim, o jornal atua apenas como uma ponte entre a polícia e o público, não tratando a informação, através de apuração e contextualização do fato.

Todos os elementos descritos permitiram aferir que a cobertura policial em Ponta Grossa contribui para o distanciamento do público no entendimento das responsabilidades políticas e estruturais envolvidas nas questões relativas a segurança pública. Essa característica soma-se ao trabalho jornalístico sobre essa editoria em outros jornais de mesmo porte e com abrangência de cobertura similar. $\mathrm{O}$ que exige estudos comparados e redes de pesquisa.

\section{CONSIDERAÇÕES FINAIS}

A análise sobre a cobertura policial de dois impressos regionais sediados em Ponta Grossa apontou que há uma falta de profissionalismo não apenas na estrutura da redação e distribuição de produção de conteúdo noticioso, mas que isso também afeta a própria cobertura jornalística de polícia e segurança pública. Esta é praticamente ausente nos dois impressos.

Os jornais apresentaram a mesma lógica de cobertura dos "setoristas", período em que cada profissional era deslocado para cobrir uma determinada área. Muitos jornalistas trabalhavam nas delegacias e plantões policiais e a pauta policial era definida, sobretudo, pelo que a polícia recebia em seus boletins de ocorrências. E o conteúdo também era associado à perspectiva policial. Os dados da reflexão proposta reiteraram essa prática ainda hoje. Quem define a pauta de polícia é a própria instituição, a apuração é centrada nas informações policiais e sem pluralidade de fontes, mesmo quando o jornalista visita o local do acontecimento. Nesse caso, a causa é que apenas o fotojornalista acompanha a ocorrência, para captar a imagem, sem tempo de realizar a apuração in loco. Pautas sobre "ações governamentais" e "justiça" são ínfimas, principalmente pela perspectiva da prevalência dos direitos dos cidadãos e do exercício de cidadania.

Outro problema da dependência das informações oficiais é que reproduz e "legitima" o discurso das instituições que controlam os poderes vigentes, se distanciando das

Comun. \& Inf., Goiânia, GO, v. 21, n. 1, p. 2-19, jan./mai. 2018 
deontologias do jornalismo e do seu compromisso com o interesse público. São coberturas que não cobram políticas públicas, não questionam o sistema vigente, nem a falta de segurança, enfim, não abordam o fenômeno, mantendo-se restritas à singularidade dos acontecimentos e sua consonância, como no caso dos acidentes.

\section{REFERÊNCIAS}

ALVIM, André Luís Toledo. Desafios na Cobertura de Segurança Pública: É possível um jornalismo interpretativo em meio às produções factuais e à pressão pelo imediatismo? 2010. 94f. Trabalho de conclusão de curso (Bacharelado em Comunicação Social) - Universidade Federal de Juiz de Fora, Juiz de Fora, 2010.

ANGRIMANI, Danilo. Espreme que sai sangue: um estudo do sensacionalismo na imprensa. São Paulo: Summus, 1995.

CERVI, Emerson Urizzi. Eleições municipais nas primeiras páginas dos jornais diários: Comparação entre produção jornalística em periódicos de municípios com conjunturas políticas diferentes e seus efeitos para a democracia de massa. In: Sociedade Brasileira de Pesquisa em Jornalismo. V. 5, n.1, 2009. Dispinível em:

<http://bjr.sbpjor.org.br/bjr/article/view/194/193> Acesso em: 21 jun. 2015.

CORREIA, Eduardo Luiz. Os "valores-notícias" característicos da narrativa policial da imprensa. Comunicação \& Inovação, São Caetano do Sul, v. 11, n. 21:(59-65) jul-dez 2010. Disponível em: <file://C:/Users/Usuario/Downloads/1181-4007-1-PB.pdf> Acessado em 26/06/2015.

DANTON, Robert. O beijo de Lamourete. Cia das Letras, 1990.

FUCCIA, Eduardo Veloso. Reportagem policial: Um Jornalismo Peculiar. Santos, SP: Realejo Edições, 2008.

GALTUNG, J. e RUGE M. A estrutura do noticiário estrangeiro: a apresentação das crises do Congo, Cuba e Chipre em quatro jornais estrangeiros. In: TRAQUINA, Nelson (org).

Jornalismo: questões, teorias e estórias. Lisboa: Veja, 1994, p.61-73.

LAGE, Nilson. Linguagem jornalística. 8.ed. São Paulo: Ática, 2006.

LIMA, Ivan. Fotojornalismo brasileiro: realidade e linguagem. Rio de Janeiro: Fotografia Brasileira, 1989. 
MCCOMBS, Maxwell. A teoria da agenda: A mídia e a opinião pública. Petrópolis, RJ: Vozes, 2009.

PARANÁ, Secretaria de Estado de Segurança Pública. Relatório estatístico criminal: Quantitativo de vítimas de crimes relativos à morte de janeiro à dezembro de 2014. Paraná segundo município e Curitiba segundo bairros. Curitiba, Fevereiro de 2015. Disponível em: <http://www.seguranca.pr.gov.br/arquivos/File/Relatorio_Mortes_PR_4trimestre2014.pdf>. Acesso em 10 de abril de 2015.

PEUCER, Tobias. Os relatos jornalísticos. Estudos em Jornalismo e Mídia, v. 1, n. 2, p.13$30,2^{\circ}$ semestre de 2004.

PONTES, Felipe S.; SILVA, Gislene. Mídia noticiosa como material de pesquisa: Recursos para o estudo de produtos jornalísticos. In: BOURGUIGNON, Jussara A; OLIVEIRA JUNIOR, Constantino. Pesquisa em Ciências Sociais: Interfaces, debates e metodologias. Ponta Grossa: Toda Palavra, 2012.

ROLIM, Marcos. A síndrome da rainha vermelha: policiamento e segurança pública no século XXI. Rio de Janeiro: Jorge Zahar / Oxford, Inglaterra: University of Oxford, Centre for Brazilian Studies, 2006.

SILVA, Gislene. Para pensar critérios de noticiabilidade. In: SILVA, Gislene; SILVA, Marcos Paulo; FERNANDES, Mario Luiz (org.). Critérios de Noticiabilidade: Problemas conceituais e aplicações (pp. 51-69). Florianópolis: Insular, 2014.

SILVA, Marcos P. A construção cultural da narrativa noticiosa: noticiabilidade, representação simbólica e regularidade cotidiana. Tese (Programa de Pós Graduação em Comunicação Social), Universidade Metodista de São Paulo, São Bernardo do Campo, 2013.

SOUSA, Jorge Pedro. Fotojornalismo: Introdução à história, às técnicas e à linguagem da fotografia na imprensa. Florianópolis, SC: Letras Contemporâneas, 2004a.

SOUSA, Jorge Pedro. Uma história crítica do fotojornalismo ocidental. Florianópolis, SC: Letras Contemporâneas, 2004b.

WAINBERG, Jacques A. Mídia e terror: Comunicação e violência política. São Paulo: Paulus, 2005. 